\title{
CAREIRO DA VÁRZEA E IRANDUBA: \\ CASOS DE METROPOLIZAÇÃO SELETIVA NO CONTEXTO DA REGIÃO METROPOLITANA DE MANAUS
}

\author{
CAREIRO DA VÁRZEA AND IRANDUBA: \\ CASES OF SELECTIVE METROPOLIZATION IN THE CONTEXT OF THE \\ METROPOLITAN REGION OF MANAUS
}

\section{CAREIRO DA VÁRZEA ET IRANDUBA: \\ CAS DE MÉTROPOLISATION SÉLECTIVE DANS LE CONTEXTE DE LA RÉGION MÉTROPOLITAINE DE MANAUS}

\section{Resumo}

Fredson Bernadino Araújo da Silva ${ }^{1}$ Marcos Castro de Lima ${ }^{2}$

\begin{abstract}
A Região Metropolitana de Manaus (RMM) constitui uma realidade jurídica, mas, por conta de não apresentar conurbação, conceitualmente ainda não pode ser enquadrada nas análises clássicas sobre o conceito científico de região metropolitana assim como do processo de metropolização do espaço e é nesta particularidade que a pesquisa se desenvolveu. O objetivo é entender as dinâmicas internas da RMM e a seletividade espacial a partir de uma análise comparativa para os casos dos municípios de Iranduba e Careiro da Várzea, relacionando ao sítio no desenrolar desse processo de metropolização do espaço. Todavia, não desassociando a importância dos consumidores do espaço para os processos de crescimento da metrópole. A discussão perpassa as bases e a construção das espacialidades nos processos de metropolização do espaço da Amazônia Ocidental. A hipótese que fundamenta esse trabalho é a de que a relação sociedadelespaço, no contexto da Amazônia, influencia significativamente o processo de produção do espaço urbano, interferindo, inclusive, na seletividade dos avanços metropolitanos apreendidos por suas distintas formas de territorialização nas estruturas urbanas. Não se trata de uma análise naturalizante, pois, no contexto da Amazônia, o regime fluvial impacta fortemente as dinâmicas das cidades e do urbano como é o caso das inundações que ocorrem na sede de Careiro da Várzea.
\end{abstract}

Palavras-Chave: Metropolização do espaço; seletividade espacial; Região Metropolitana de Manaus; Iranduba; Careiro da Várzea.

\begin{abstract}
The Metropolitan Region of Manaus (RMM) is a legal reality, but, due to its lack of conurbation, conceptually it still cannot be framed in the classic analyzes of the scientific concept of the metropolitan region as well as of the process of metropolitan space and it is in this particularity that the research has developed. The objective is to understand the internal dynamics of RMM and the spatial selectivity from a comparative analysis for the cases of the municipalities of Iranduba and Careiro da Várzea, relating to the site in the course of this process of metropolitan space. However, it does not disassociate the importance of

\footnotetext{
${ }^{1}$ Mestrando e Bacharel em Geografia pela Universidade Federal do Amazonas - UFAM. Membro do Laboratório de Geografia Humana - LAGEHU/UFAM. E-mail: fbernardino1997@gmail.com

${ }^{2}$ Professor da Pós-graduação e do Departamento de Geografia da Universidade Federal do Amazonas. Doutor em Geografia Humana pela Universidade de São Paulo. Membro do Laboratório de Geografia Humana -

LAGEHU/UFAM. E-mail: castrolmar@bol.com.br
} 
space consumers for the growth processes of the metropolis. The discussion runs through the bases and the construction of spatialities in the processes of metropolization of space in the Western Amazon. The hypothesis that underlies this work is that the society/space relationship, in the context of the Amazon, significantly influences the urban space production process, even interfering in the selectivity of the metropolitan advances seized by its different forms of territorialization in urban structures. This is not a naturalizing analysis, because, in the context of the Amazon, the fluvial regime has a strong impact on the dynamics of cities and urban areas, such as the floods that occur at the Careiro da Várzea headquarters.

Keywords: Metropolization of space; spatial selectivity; Metropolitan Region of Manaus; Iranduba; Careiro da Várzea.

\section{Résumé}

La Région Métropolitaine de Manaus (RMM) est une réalité juridique, mais, en raison de son manque d'agglomération, elle ne peut toujours pas être encadrée conceptuellement dans les analyses classiques du concept scientifique de la région métropolitaine ainsi que du processus d'espace métropolitain et c'est dans cette particularité que la recherche s'est développée. L'objectif est de comprendre la dynamique interne de RMM et la sélectivité spatiale à partir d'une analyse comparative des cas des communes d'Iranduba et de Careiro da Várzea, relatifs au site au cours de ce processus d'espace métropolitain. Cependant, il ne dissocie pas l'importance des consommateurs spatiaux pour les processus de croissance de la métropole. La discussion parcourt les bases et la construction des spatialités dans les processus de métropolisation de l'espace en Amazonie occidentale. L'hypothèse qui sous-tend ce travail est que la relation sociétélespace, dans le contexte de l'Amazonie, influence significativement le processus de production de l'espace urbain, interférant même dans la sélectivité des avancées métropolitaines saisies par ses différentes formes de territorialisation dans les structures urbaines. Il ne s'agit pas d'une analyse naturalisante, car, dans le contexte de l'Amazonie, le régime fluvial a un fort impact sur la dynamique des villes et des zones urbaines, comme les inondations qui se produisent au siège de Careiro da Várzea.

Mots-clés: Métropolisation de l'espace; sélectivité spatiale; Région Métropolitaine de Manaus; Iranduba; Careiro da Várzea.

\section{INTRODUÇÃO}

O processo de metropolização do espaço constitui uma variável do processo de urbanização que ganha ênfase com a globalização, visto que a metrópole contém especificidades locais que lhe caracterizam, também possui as características globais. Nesse sentido, como expressão socioespacial, a metropolização do espaço revela os traços, tempos e dinâmicas da metrópole contemporânea, em variadas escalas. No caso do processo de metropolização na Amazônia Ocidental, especificamente na Região Metropolitana de Manaus (RMM), há que se considerar as dinâmicas relacionadas ao meio natural, especialmente no que diz respeito à dinâmica fluvial ${ }^{3}$, cuja expressão maior reside no regime dos rios. Essa dinâmica fluvial pode influenciar na produção do espaço, e, neste caso, nos vetores de crescimento da metrópole.

A pesquisa teve como recorte espacial os municípios de Careiro da Várzea e Iranduba, limítrofes à metrópole Manaus e os que possuem as sedes municipais mais próximas à metrópole. Contudo, este recorte

\footnotetext{
${ }^{3}$ Por dinâmica fluvial entendemos os processos que envolvem os regimes de enchente e vazantes dos rios da região, pois estes influenciam fortemente na expansão ou não das áreas urbanas visto que muitas cidades têm seus espaços inundados parcial ou totalmente na cheia. E muitas também têm dificuldades de acesso e abastecimento no período da seca (LIMA, 2008).
} 
revela a diferença existente entre áreas singulares da RMM, cujo o arranjo espacial influencia na seletividade por parte das políticas públicas e da expansão do capital, especialmente no que se refere ao setor imobiliário. Em Iranduba, percebe-se um nítido processo de metropolização do espaço, pois ocorre a reestruturação advinda das mudanças ali ocorridas, especialmente depois da construção da ponte sobre o rio Negro (SOUSA, 2013). Esse objeto, a Ponte Jornalista Phelippe Daou, mais conhecida como Ponte (do) Rio Negro, rompe com a descontinuidade entre a metrópole e o município de Iranduba. Tanto as ações desenvolvidas pelo Estado: duplicação da rodovia Manoel Urbano (AM-070) que interliga Manaus a Iranduba, como implantação de estabelecimentos de ensino, feiras e o zoneamento de um novo campus da Universidade do Estado do Amazonas (UEA), intitulado como Cidade Universitária da UEA, como as iniciativas privadas nas ações dos setores fundiários e imobiliários, bem como a ampliação do setor de comércio e serviços, que não deixam dúvidas quanto à metropolização do espaço.

Por outro lado, no município de Careiro da Várzea, não se percebe a mesma dinâmica. Ali não há a busca pela terra com vistas à incorporação e ampliação do setor imobiliário. Tampouco se observa mais intensamente as políticas públicas oriundas das ações do Estado, com particular atenção na esfera estadual. Trata-se de um município cuja sede está localizada em uma área de várzea, com um pequeno núcleo urbano, onde a densidade demográfica municipal é de 9,09 hab/ $/ \mathrm{km}^{2}$ (IBGE, 2010), além de haver poucas áreas para se expandir, com especial atenção no mercado imobiliário. Ali o regime sazonal de enchentes e vazantes faz com que, em tempos de enchentes excepcionais, ou seja, enchentes que ultrapassam os 29 metros acima do nível do mar, a cidade fique inundada por completo. Em síntese, aquilo que Lima (2014) denomina de "cidade anfíbia"4.

Então, se em Iranduba, onde a estrutura é oriunda do período terciário, salvo algumas exceções, não permite as inundações, do contrário, em Careiro da Várzea, a área é de estrutura quaternária e, portanto, é sujeita às inundações por cerca de 6 meses ao ano. Essa observação leva ao entendimento de que o sítio, especialmente o regime fluvial, nesse caso, influencia na seletividade espacial à metropolização do espaço em sua forma mais concreta e material, via reestruturação socioespacial. Há, nesse sentido, uma seletividade socioespacial que permite constatar que em uma região metropolitana extensa como a RMM, o processo de metropolização do espaço ocorre em locais "não aleatórios" e "não específicos", cuja influência do regime fluvial e da estrutura geomorfológica não podem ser olvidados.

A RMM, por apresentar um território juridicamente extenso, possui expressiva heterogeneidade socioespacial em seu território, o que envolve as várzeas e terras firmes ${ }^{5}$ que, nesse sentido, parte da região metropolitana é composta de áreas inundáveis, como é o caso da sede municipal de Careiro da Várzea. Assim, a RMM é extensa, mas sua heterogeneidade socioespacial faz com que haja a seletividade na busca

\footnotetext{
${ }^{4}$ Não se trata de uma naturalização do espaço urbano. O termo cidade anfíbia constitui uma analogia aos anfíbios pelo fato de que a cidade de Careiro da Várzea permanece totalmente inundada no período da cheia com os seus habitantes tendo que construir pontes que substituem as ruas, sendo que estas emergem novamente no período da seca.

${ }^{5}$ De forma introdutória, diz-se que as várzeas são áreas inundáveis e as terras firmes são áreas não inundáveis sob o regime fluvial no contexto amazônico (STERNBERG, 1998).
} 
tanto pelo Estado quanto pelo capital privado pelas terras de maior potencial lucrativo e, neste caso, também aos processos relacionados à dinâmica fluvial.

Nesse contexto, o objetivo deste artigo é de compreender o processo de metropolização do espaço que ocorre na RMM a partir da seletividade espacial tendo uma análise comparativa entre os municípios de Iranduba e Careiro da Várzea. Para isso: a) analisa-se sobre os princípios que marcam as singularidades da área de estudo; b) apreende-se a questão relacional do processo de metropolização do espaço no contexto da RMM; c) entende-se a seletividade espacial e a importância para a metropolização do espaço no contexto da Amazônia Ocidental.

Optou-se aqui por uma abordagem sob três dimensões de entendimento: a) compreensão jurídica, que legitima a existência da RMM do ponto de vista legal e consequentemente das ações recorrentes tanto do Estado quanto do setor privado; b) entendimento ideológico, que define os discursos produzidos e os interesses dos grupos sociais, bem como o entendimento da ação dos agentes modeladores e consumidores do espaço urbano/metropolitano (CORRÊA, 2003) e; c) dimensão política por agregar o discurso de "desenvolvimento social" na Amazônia, bem como ações executivas que reconfiguram o espaço geográfico, em especial, no que se refere à intervenção do Estado, a partir de políticas públicas que induzem o processo de metropolização do espaço. Busca-se enfatizar a imbricação das três dimensões apontadas no que tange a relação entre a geomorfologia fluvial, a sociedade e o processo de metropolização do espaço no contexto da Amazônia Ocidental.

Os procedimentos investigatórios adotados foram um levantamento bibliográfico sobre os termos conceituais de cidade, urbano, metropolização do espaço, região metropolitana e geomorfologia fluvial com destaque para a Amazônia, visando adquirir arcabouço teórico para subsidiar as etapas posteriores. Também foi realizado pesquisa no Plano Diretor Integrado da Região Metropolitana de Manaus (PDIRMM) que data do ano de 2010, que indica as áreas prioritárias ao Estado no processo de "integração metropolitana" e da seletividade espacial e sua articulação com o meio natural.

Foram realizadas pesquisas de campo em Iranduba e Careiro da Várzea. Estas permitiram, a partir da observação empírica, um entendimento mais amplo do processo de metropolização do espaço e quais os seus níveis em cada um desses municípios, bem como os níveis de influência do regime fluvial nas dinâmicas da produção do espaço urbano.

Procedeu-se à elaboração mapas temáticos qualitativos que permitem a visualização e espacialização da intensidade ou ausência do processo de metropolização do espaço nos municípios do recorte espacial. Ocorreu ainda o registro fotográfico que permite a visualização dos objetos geográficos oriundos da atividade do Estado quanto do capital privado. 


\section{A METRÓPOLE E A "INTEGRAÇÃO METROPOLITANA": BREVE CONTEXTUALIZAÇÃO SOBRE A ÁREA DE ESTUDO}

A RMM é composta pelos municípios de Presidente Figueiredo, Novo Airão, Rio Preto da Eva, Itacoatiara, Manacapuru, Iranduba, Careiro da Várzea e a metrópole, Manaus, sendo os três últimos o cerne deste trabalho (Mapa 01).

Mapa 01: Mapa de localização dos municípios de Manaus, Iranduba e Careiro da Várzea na RMM.

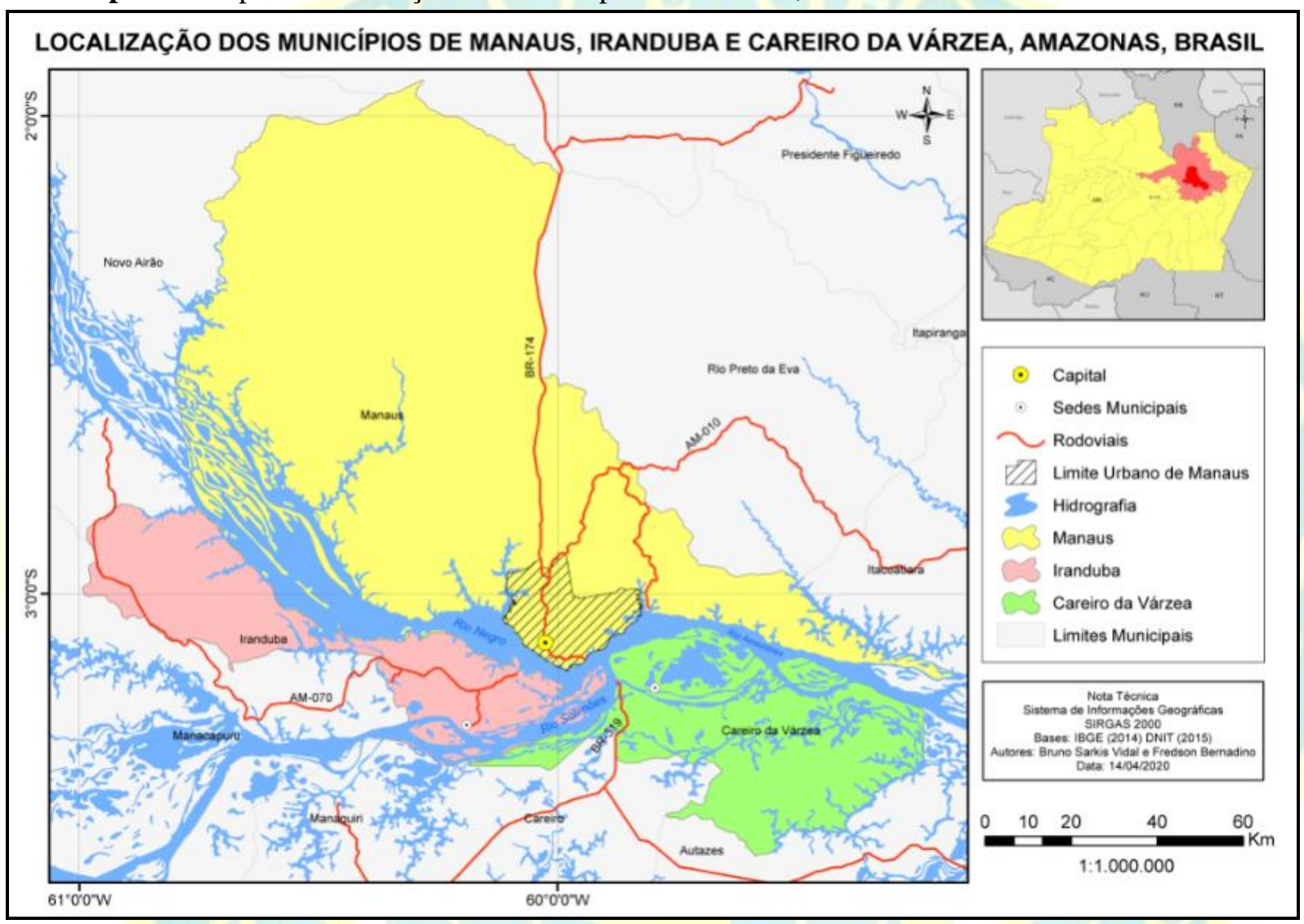

Fonte: IBGE (2014), DNIT (2015). Elaboração: Vidal e Bernardino (2020).

Manaus é uma metrópole singular, uma cidade interlocutora da relação global-local no coração da Amazônia Ocidental. Ao pensar a metropolização do espaço no contexto da Amazônia a qual destoa do restante do Brasil, faz-se necessário analisar a expressão socioespacial dessa região, assim, elaborando um paralelo com a dimensão jurídica que institui a RMM. Não somente, para pensar a metropolização do espaço na região, deve-se ter claro os movimentos de urbanização e ocupação do recorte espacial estudado.

A ocupação na região Amazônica se dá, como afirmam Lima (2014) e Sousa (2013), em primeira instância nas margens dos principais rios e em seguida pelas políticas de integração no Regime Militar, período político entre os anos de 1964 e 1985. O padrão de urbanização é a dispersão de núcleos urbanos em uma extensa área, a concentração de pontos urbanos não é uma característica predominante na Amazônia 
Ocidental. Essa dispersão pressupõe dois polos: Belém - PA (Amazônia Oriental) e Manaus - AM (Amazônia Ocidental).

Manaus tem um processo de urbanização e de inserção na lógica capitalista-global principalmente no Auge do Ciclo da Borracha que ocorre entre os anos de 1879 e 1912, período em que a cidade viveu uma reestruturação aos moldes eurocêntricos da época, sendo denominada como a "Paris dos Trópicos", termo que ressalta a figura do exótico que a Amazônia carrega nessa época.

Conforme Lima (2014), a base moderna, para a consolidação da metrópole da Amazônia Ocidental só aparece com a instituição da Zona Franca de Manaus (ZFM) pelo Decreto-Lei № 288, de 28 de fevereiro de 1967, o que viabilizou a instalação de empresas e um polo industrial na cidade, intensificando a concentração da população na capital. Ainda segundo o autor, o resultado da Zona Franca foi a contradição do padrão urbano "disperso e concentrado", onde há forte dispersão dos núcleos urbanos na maior Unidade Federativa do país e, ao mesmo tempo, forte concentração do poder, riquezas e fator demográfico na capital. O processo de instituição da RMM seria outro momento, que marca a periodização de Manaus como metrópole moderna, no que Lima (2014) afirma:

[..] a Lei Complementar 052/2007 [que institui a RMM] veio produzir uma nova realidade, vindo também superar o urbano e incorporar o metropolitano, como fato jurídico, e induzindo a um processo de metropolização. Nesse sentido, ocorreu o fato em que " $o$ amanhã veio ontem", ou seja, institui-se política e juridicamente uma RM [Região Metropolitana] para depois se induzir a uma produção socioespacial metropolitana (LIMA, 2014, p. 285).

Assim, a institucionalização da RMM foi, em síntese, uma proposta de indução do processo de metropolização do espaço. Na tomada de decisão, é invariável o fator político dado pela ação do Estado, nesse caso, imbricado ao fator jurídico, além do fator ideológico compreendendo o interesse dos grupos, mais particularmente os promotores imobiliários. Para isso, Sousa (2013) explica que os interesses dos grupos dos promotores imobiliários tendem a um crescimento da metrópole manauara com foco de desenvolvimento para o sul, em primeiro momento Iranduba e, consequentemente para Manacapuru. Para superar o obstáculo fluvial, faz-se a Ponte Jornalista Phelippe Daou e entre outras obras. Essas adequações infraestruturais conduzem outros processos espaciais:

Essas ações [de infraestrutura] também incentivam o estabelecimento de indústrias e a migração de pessoas criando assim novos fluxos econômicos e novas territorialidades no espaço urbano-regional e contribuindo, em geral, para a valorização dos terrenos (SOUSA, 2013, p.236).

Os processos espaciais descritos por Sousa (2013) se referem especialmente sobre o vetor metrópole ao município de Iranduba. Portanto, a reestruturação do espaço construído interfere na produção socioespacial. As obras de reconfiguração da região são motivadas por uma perspectiva e idealismo de desenvolvimento da Amazônia, levando a expansão urbana para a escala do local ao regional e apresenta distintas propriedades de sítio. 
Casos de metropolização seletiva no contexto da Região Metropolitana de Manaus

\section{AMAZÔNIA OCIDENTAL E PROCESSOS ESPACIAIS}

$\mathrm{O}$ entendimento das relações da ocupação e sítio $^{6}$ não podem ser olvidadas no que se refere à produção do espaço urbano, isto é, face aos discursos que apregoam o primado do capital e da técnica sobre todos os lugares (CATAIA, 2001). Não obstante, é fato que o capital e a técnica estão presentes de múltiplas formas, e que isso pouco depende das características dos lugares. Por outro lado, esse fato deve ser problematizado quando se considera a geografia específica da Amazônia, especialmente em sua estrutura geomorfológica e em seu regime fluvial. Essas características, se analisadas à luz do processo de metropolização do espaço, podem revelar a seletividade espacial na busca dos lugares onde o processo de metropolização do espaço pode ou não ocorrer. Dessa forma, não é a existência da região metropolitana como ente jurídico que garante a metropolização do espaço, sobretudo do ponto de vista mais material em toda a sua extensão territorial, até porque esta é superlativa.

As características de sítio constituem importantes influenciadores de um processo que tradicionalmente é analisado quase que exclusivamente pela via econômica. Trata-se de analisar um fenômeno como a metropolização do espaço, com escopo na influência que o sítio, a questão geomorfológica e o regime fluvial, exercem sobre este fenômeno "socioespacial". Isto é, a pesquisa vai no sentido de tentar entender a heterogeneidade de uma região complexa como a Amazônia a partir da RMM, tanto ao nível do avanço do processo de metropolização do espaço quanto no nível de sua estrutura de sítio que constitui relevante elemento de análise. Assim, o processo de metropolização do espaço, no contexto da RMM, não constitui algo que ocorre de forma ubíqua, como a tradição de sua análise sustenta.

Para Corrêa (2003) a seletividade relativa ao espaço parece a partir da complexidade socioespacial e a intensifica. Refere-se às práticas espaciais de promoção de áreas em detrimentos de outras haja visto a distribuição de recursos e objetos (CORRÊA, 1992; MOREIRA, 2017; LENCIONI, 2012, 2017). Essa perspectiva parte do entendimento que as relações de poder são dadas espacialmente, visto possuir caráter de materialização, como na produção de centralidades e a consequente capacidade de atração (ROCHA, 2012).

Dessa forma, uma compreensão a partir da seletividade espacial apresenta a relevância de uma geografia total, em que as dimensões humanas se imbricam com as dimensões da natureza, não significando uma abordagem naturalizante, mas produzindo espaços seletivos e conflituosos, onde de um lado está a metropolização do espaço em curso em Iranduba com obras de expressiva envergadura e, de outro lado, espaços que as obras e estruturas estatais e privadas pouco chegam, ou quando chegam, existem apenas em formas que não permitem uma "reestruturação produtiva" (LENCIONI, 2012, 2017) de fato, que por sinal estão contidas nas propostas do PDIRMM (2010). Essa consonante leva a indagação: Para onde a metrópole da Amazônia Ocidental está crescendo? Com a construção da Ponte Jornalista Phelippe Daou fica mai evidente, à cidade de Iranduba, ao sul de Manaus, é foco dos avanços.

\footnotetext{
${ }^{6}$ Por sítio entendemos como o terreno que apresenta padrões geomorfológicos, padrões de drenagem e amenidades fisiográficas onde os processos espacial da sociedade ocorrem. 
No caso do Estado do Amazonas, LIMA (2014) ressalta que apesar de juridicamente a região metropolitana ser legitimamente institucionalizada, do ponto de vista conceitual, entretanto, ela não se circunscreve nas análises clássicas relativas ao processo de metropolização do espaço. Presenciamos o crescimento da expressão espacial urbana, caminhando para metropolização do espaço a partir da metrópole de Manaus à cidade de Iranduba, distantes 40,1 quilômetros e com um tempo médio de 49 minutos de percurso via Ponte Jornalista Phelippe Daou. A ponte, pode-se afirmar, não existe somente de forma material, mas também de forma simbólica no processo de articulação entre Manaus-Iranduba.

Entretanto, partimos de uma indagação, para explicar tais relações: qual o porquê de Iranduba, especificamente, ter apresentado um crescimento da expressão espacial urbana, nesse caso, tendência em questão da conurbação - ainda não consagrada, mas em vias de consolidação - comparada a outras cidades próximas a capital Manaus? Tomamos, então, como contraponto a cidade do Careiro da Várzea, distante 23 quilômetros e com tempo médio de percurso de 30 minutos via balsa com relação à metrópole. Apesar de Careiro da Várzea ter quase a metade do distanciamento de Manaus com relação a Iranduba, a primeira cidade não apresenta interligação estrutural viária terrestre e poucas expressões simbólicas para tal no comparável de Iranduba à Manaus. Não se verifica avanços na exploração do acesso natural já estabelecido, ou melhor, a constituição de uma hidrovia. O contraste é principalmente marcado desde o dia 24 de outubro de 2011, data da inauguração da Ponte, um marco viário, que contribuiu para a ruptura da descontinuidade espacial entre a metrópole e o município de Iranduba.

Enquanto análise territorial da RMM, enfatiza-se a espacialidade amazônica que envolve uma metafísica regional, como no movimento da sociedade e a produção do espaço em relação aos processos urbanos que funcionam como indicadores para o entendimento das territorialidades e seus caminhos nesse importante eixo metropolitano regional amazônico. Nesse sentido o cerne recai na relação entre a sociedade e a natureza, onde se utiliza uma visão da Geografia Urbana e as definições que esta abrange para processar os fatos que a realidade manifesta, valorizando a diversidade natural e a particularidade cultural dos lugares, os pontos de riqueza que a Amazônia possui. Portanto, a apreensão das transformações socioespaciais, sob perspectiva metropolitana, são uma forma de pretendida desmistificação dos desdobramentos sociais cobrindo aspectos estruturantes: moradia, fluxos, padrão de aglomeração urbana e etc.

\section{NOÇÕES SOBRE O PODER DA METRÓPOLE E SUAS INFLUÊNCIAS}

A discussão sobre as metrópoles é tão antiga quanto a existência do fenômeno, a importância das metrópoles fica mais evidente, por exemplo, no processo de colonização, onde, de forma genérica, as relações de poder se deram na articulação que partia da metrópole para as áreas colonizadas, pois era na metrópole em que as decisões eram tomadas. Já em uma rede urbana a metrópole também desempenha uma influência sobre as cidades adjacentes, onde a zona de influência mais direta é denominada como região metropolitana que aparece, do ponto de vista socioespacial, como produto e expressão concreta da 
metropolização do espaço. Ou seja, as cidades que circundam a metrópole, locus do qual emana o poder, voltam-se ao centro de poder e de relações informacionais e econômicas, já a metrópole, por sua vez, voltase ao restante do mundo (metropolitano), isto é, a metrópole, especialmente na contemporaneidade, é um fixo geográfico que se articula com a globalização.

Consagrando o processo de metropolização do espaço do ponto de vista da unidade material e da fisiografia, tem-se a conexão entre duas ou mais cidades por meio da circulação regular e pela conurbação. Assim, havendo a interação por meio dos fluxos e dos fixos. Nesse sentido, ocorre relações materiais e imateriais entre a metrópole e demais cidades, o que caracteriza uma região metropolitana conurbada. No caso da conurbação, é observável na formação do tecido urbano contínuo, assim sendo, na integração dos avanços da paisagem urbana entre duas cidades distintas. O processo de metropolização do espaço tem função de abastecimento demandado do crescimento demográfico dos centros urbanos e pelo interesse imobiliário que este gera, e não somente, esse processo é seletivo.

Porém, conforme Lima (2014) a questão que deve ser colocada como singular à RMM é a da institucionalização de uma região metropolitana que precede ao processo de metropolização do espaço do ponto de vista material. O Estado, sobretudo o governo do estado do Amazonas, executa um plano de delimitação e inserção da área em um modelo de região metropolitana, sob o intuito de recebimento de maiores repasses da União. Apesar da conurbação ainda não ser um fato, os fluxos e a leitura de uma unidade material entre Manaus e Iranduba é realizada atualmente (EHNERT, 2011).

Sobre a metropolização do espaço enquanto destaque de 'processo', este é um elemento socioespacial que metamorfoseia o território, é, como afirmamos anteriormente, imanente à globalização, muito embora não se restringe apenas à fase do capitalismo. Portanto, a metropolização do espaço é um elemento que pode ser interpretado como um reflexo da globalização (LENCIONI, 2012, 2017). E por globalização, compreende-se como a tendência de homogeneização das relações sociais a nível global. Lencioni $(2012,2017)$ traz a ideia desse processo como "metamorfose socioespacial", pois promove transformações profundas onde se territorializa e ocorre de fora para dentro. Há uma penetração da globalização, tendo como face a metropolização do espaço, alterando os lugares e territorialidades pretéritas.

Essa penetração é, no caso da RMM, a inserção de um discurso estatal de desenvolvimentismo para a região. Para Lima (2014, p. 289), o Estado, neste caso, coloca a emergência de uma espécie de "vocação metropolitana" sob o âmbito ideológico do modelo de desenvolvimento de região metropolitana à brasileira, desconsiderando as condições socioespaciais preexistentes, o que pode ser verificado sobre Iranduba, como exemplo, em um dos mapas contidos no PDIRMM (2010) a seguir (FIGURA 01): 
Figura 01: Cartograma de "tendências de vocações" de Iranduba

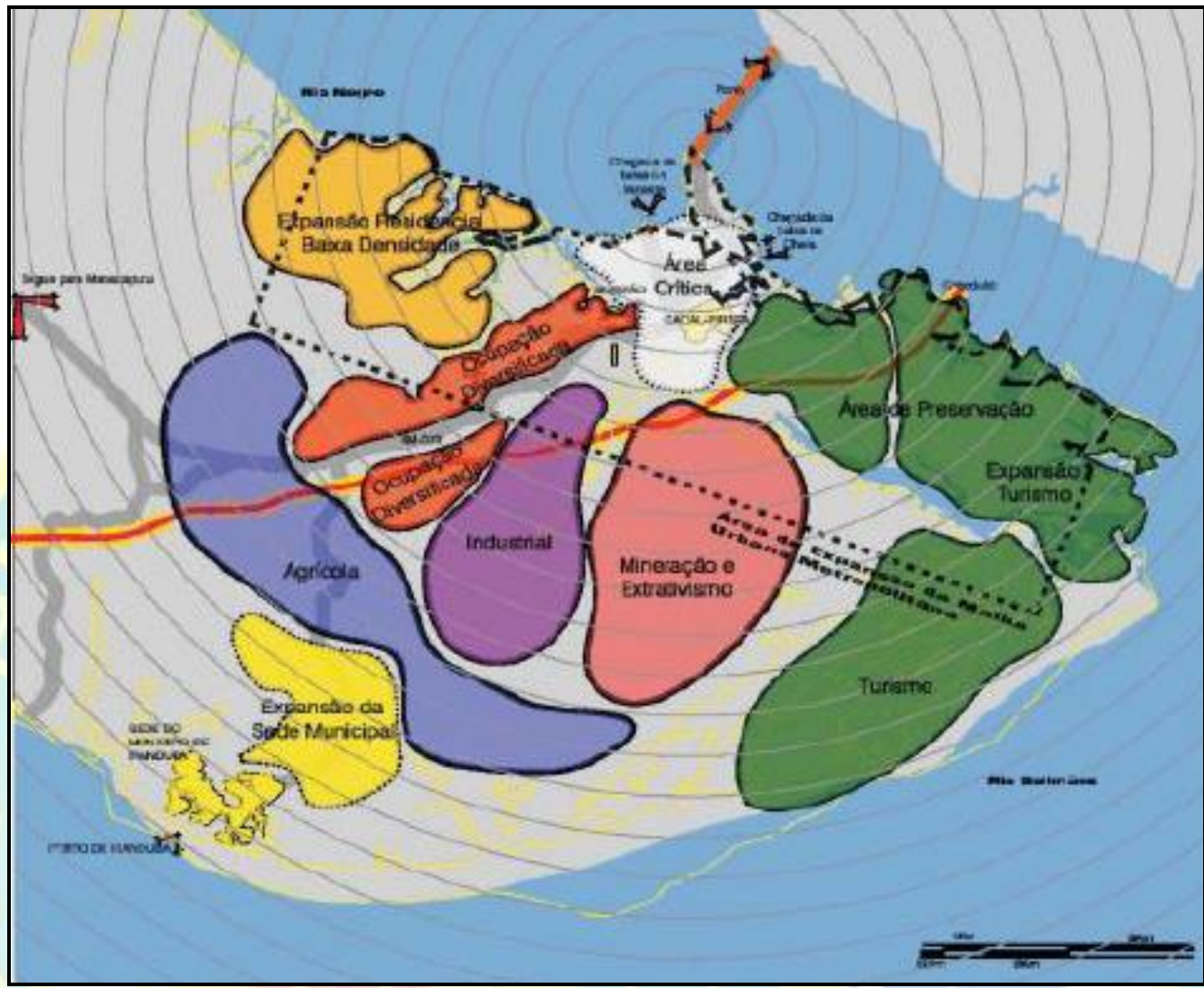

Para explicar essa dinâmica, apoiamo-nos em Di Méo (2008) que trata do poder (político) das metrópoles, sendo historicamente cidades interlocutoras das trocas e do fluxo das cidades que essas 'dominam'. Dessa forma, fornece serviços raros e estratégicos, integrando as demais cidades ao seu movimento e demandas. O autor elenca diversas dimensões de importância da metrópole: política, ideológica, cultural e econômica. Política e juridicamente, sendo a metrópole a fração do espaço que concerne o poder no mais alto nível; Economicamente, inserindo a região metropolitana às suas trocas; Ideológica e culturalmente, disseminando um ritmo de ação às cidades relacionadas. É nessa dinâmica que as metrópoles "constroem uma rede mundial, um tipo de tecido de centralidades combinando lógicas hierárquicas e resilientes" (DI MÉO, 2008, p. 1).

Essa lógica pode ser verificada na área de estudo. A propositiva é dada na metrópole e a "região" é repartida com certo nível de arbitrariedade, sem levar em conta a construção socioespacial das municipalidades em função de um projeto particular que articula interesse tendo em vista o empresariado imobiliário, a proposta política estatal e, finalmente a ratificação jurídica que dá marcações para as práticas espaciais. Um dos resultados dessa dinâmica de interesses é a espacialização das "tendências de vocações" (FIGURA 01).

Ainda segundo Di Méo (2008), a metrópole atua como uma grande reorganizadora do espaço geográfico, coordenando as atividades em nível de regionalização, tem-se a região metropolitana. $\mathrm{O}$ autor 
chama a atenção para a dicotomia das metrópoles de centro e das de periferia, o que do ponto de vista locacional, as metrópoles do sul quando comparadas às do norte, são subjugadas, exercendo menor poder político, econômico e como consequência, menor influência ideológica. Nessa perspectiva, a globalização mais uma vez aparece como condicionante maior do processo de metropolização do espaço. Manaus, além de estar inserida em um contexto de metrópole de periferia por estar no Sul Global, ainda se enquadra em uma realidade de periferia metropolitana nacional, haja vista que as metrópoles São Paulo e Rio de Janeiro apresentam muitas centralidades em várias matizes das instâncias social, política e econômica (CATAIA, 2001; THÉRY e MELLO-THÉRY, 2014). Isto significa que Manaus exerce influência regional, não obstante, sendo, de forma geral, influenciada por um circuito global (e nacional). Essa influência pode ser mais clara na questão cultural nos comportamentos metropolitanos, alcançando também outros matizes. Dessa forma se estabelecem os espectros do denominado Sul Global frente à classificação de seu congênere do Norte, espectro este reproduzido também na escala do território nacional.

Uma dessas características do Sul Global é a desigual formação socioespacial brasileira que pode ser demonstrada pelo Relatório do Desenvolvimento Humano (PNUD, 2019), em que o Brasil marcou 53,3 pontos no índice de Gini, obtendo a colocação de $79^{\circ}$ entre as medidas de IDH. Nesta posição, encontra-se entre os "países com alto IDH", porém esteve entre os 10 países com maior coeficiente de Gini, portanto, dos mais desiguais em distribuição de renda per capita.

Essa desigualdade traduz os processos espaciais, também produzidos desigualmente no contexto da metrópole, visto que constitui uma expressão socioespacial de uma sociedade desigual, produzindo espaços desiguais e fragmentados. No caso do processo de metropolização não é diferente. A metamorfose socioespacial que ocorre é dada numa lógica de metropolização seletiva (LIMA, 2014). Bem como explica Lencioni $(2012$, 2017), a primeira etapa da metropolização do espaço é a seletividade espacial. No caso manauara, os principais agentes por trás do processo são os promotores imobiliários, o Estado (governo estadual) e os proprietários latifundiários (LIMA, 2014; SOUSA, 2013). Enfim, trata-se de um campo de disputas e interesses na produção do espaço, neste caso, um espaço metropolizado de poder, que se estabelece sobre antigas espacialidades não metropolizadas.

Essa noção traz uma concepção da RMM mais complexa, mas pode ser explicada por Romanelli e Abiko (2011) que definem a metropolização, sobretudo por meio do modelo de região metropolitana, como um fenômeno que não se limita somente aos segmentos ideológico e político, embora estes sejam constantes, os autores defendem que "a metrópole não é [somente] uma entidade política, mas é um território que faz sentido para inúmeros atores e atividades, dependendo de políticas integradas de desenvolvimento urbano", isto é, um elemento de planejamento e estruturação político-social, em outros termos, de organização urbana, que tem o Estado como agente-hegemônico regulador e promotor, que exerce poder e promove rearranjos espaciais no território. 


\section{SELETIVIDADE ESPACIAL EM IRANDUBA E CAREIRO DA VÁRZEA}

Como já foi colocado, a metropolização do espaço é uma face da globalização, onde se percebe alteração da morfologia dos espaços. Lencioni $(2012,2017)$ interpreta esse processo por meio da seguinte tríade: globalização, reestruturação produtiva e metamorfose metropolitana. A globalização constitui um foco principal das reflexões sobre as metrópoles; A reestruturação produtiva é relativa às penetrações e alterações da globalização na organização social (por exemplo, no mundo do trabalho); e a metamorfose metropolitana compreende as reestruturações sofridas pelas localidades e o espaço geográfico.

Ao conceber essa tríade para a realidade da RMM, o processo de transformação socioespacial que ocorre entre a metrópole Manaus e o município de Iranduba fica mais evidente. Dessa forma, a metrópole constitui a primeira, em sua zona de influência, a receber os movimentos da globalização especialmente na questão informacional. A reestruturação produtiva se refere ao uso dos espaços, isto é, as transformações que ocorrem da metrópole Manaus ao município de Iranduba especialmente que pode ser "vetorizada" pela Ponte Jornalista Phelippe Daou. E, a metamorfose socioespacial é a conjuntura de reinvenção do perfil socioespacial e econômico da população, além de engendrar a inserção do modo de vida metropolitano sobre espaços que antes não eram identificados como tal, sendo que:

[...] toda a complexidade que marca as ações por trás da instituição da Região Metropolitana de Manaus, [...] permite afirmar que as ações do estado e do setor imobiliário entre a metrópole e Iranduba, constituem somente um aspecto desse processo, que por ser o mais evidente em sua expressão socioespacial, tende a parecer o único, como adequação do espaço urbano-regional à reprodução do capital. Mas isso é só aparentemente, pois em outras áreas da RMM isso não ocorre, como é o caso da cidade de Careiro da Várzea (LIMA, 2014, p. 224).

Nesse sentido, a seletividade espacial é mais evidente em Iranduba, cujas estruturas espaciais permitem o estabelecimento de novos objetos geográficos que expressam o processo de metropolização do espaço, como a duplicação da rodovia Manuel Urbano (AM-070), da ampliação do volume do comércio e serviços, da ampliação da circulação de veículos e da nova realidade do setor imobiliário, com a construção de habitacionais e comercialização de terrenos, especialmente nas margens das rodovias Manuel Urbano e Carlos Braga. A mesma realidade não ocorre no município de Careiro da Várzea, uma cidade localizada

[...] a $25 \mathrm{~km}$ de Manaus e uma das menores do Brasil com cerca de mil habitantes em seu pequeno núcleo urbano, faz parte da Região Metropolitana de Manaus e está localizada numa ilha (Ilha do Careiro) um terraço fluvial de formação quaternária, considerada uma várzea alta, mas que devido às cheias excepcionais como as de 1953, 2009 e 2012, inunda, levando os habitantes deste pequeno núcleo com o status de cidade a construírem assoalhos de madeira levados, dentro de suas próprias casas, bem como nas ruas inundadas [grifo do autor] (LIMA, 2014, p. 224).

Conforme citado acima, as condições naturais que envolvem a dinâmica fluvial (enchentes e vazantes) no rio Amazonas, constitui impeditivo ao avanço das forças que permitem o processo de metropolização do espaço. As condições do terreno, não são favoráveis à atuação do setor imobiliário, tão 
presente em Iranduba, trata-se de uma questão comparativa e de seletividade entre duas realidades próximas em relação à metrópole e no contexto da RMM. O entorno e a própria pequena cidade do Careiro da Várzea é formado por terrenos inundáveis e o espaço da própria cidade não pode expandir horizontalmente em função disto. Os meios técnicos à subversão dessa realidade podem ser instrumentalizados, porém, em Iranduba, é possível a apropriação pelo setor imobiliário sem a necessidade de maiores gastos, como demonstram os estudos de caso de Sousa (2013) e Braga (2019).

É importante lembrar que para os usos da terra no meio amazônico, o qual compreende a maior bacia hidrográfica do planeta, o fator fluvial ganha destaque para o entendimento da natureza e consequemente da relação desta com a sociedade, influenciando fortemente o processo de seletividade socioespacial no que se refere à expansão de objetos geográficos no processo de metropolização. Esta particularidade nem sempre é compreendida quando se analisa este processo de metropolização, pois quase sempre é entendido como um processo linear, contínuo, onde o meio natural em quase nada interfere.

Na Amazônia Ocidental, no contexto da RMM, esta realidade da influência do meio natural ocorre, pois a dinâmica fluvial e o regime dos rios influenciam diretamente o processo, até porque as dimensões territoriais superlativas assim o permitem, visto que há disponibilidade de terras, no caso de Iranduba, que não sofrem com a sazonalidade de enchentes e vazantes, onde há o avanço do setor imobiliário e demais setores que compõem a expressão espacial da metropolização.

No que concerne ao aspecto geológico da área aqui considerada, evidencia-se parte da heterogeneidade espacial da RMM. Em Manaus e Iranduba, há a prevalência da Formação Alter do Chão, em sua maioria não sujeita às inundações sazonais, o que propicia uma continuidade, em nível de terrenos entre os municípios. Já Careiro da Várzea, conforme já apontado acima, é diferente neste sentido, dispondo de formação mais recente, os Aluviões Holocênicos, conhecidos regionalmente como "áreas de várzea" ou seja, relativamente pouco consolidados e sujeitos às inundações anuais oriundas dos regimes de enchente e vazante que ocorrem anualmente no rio Amazonas (Mapa 02). 
Mapa 02: Geologia da área de estudo.

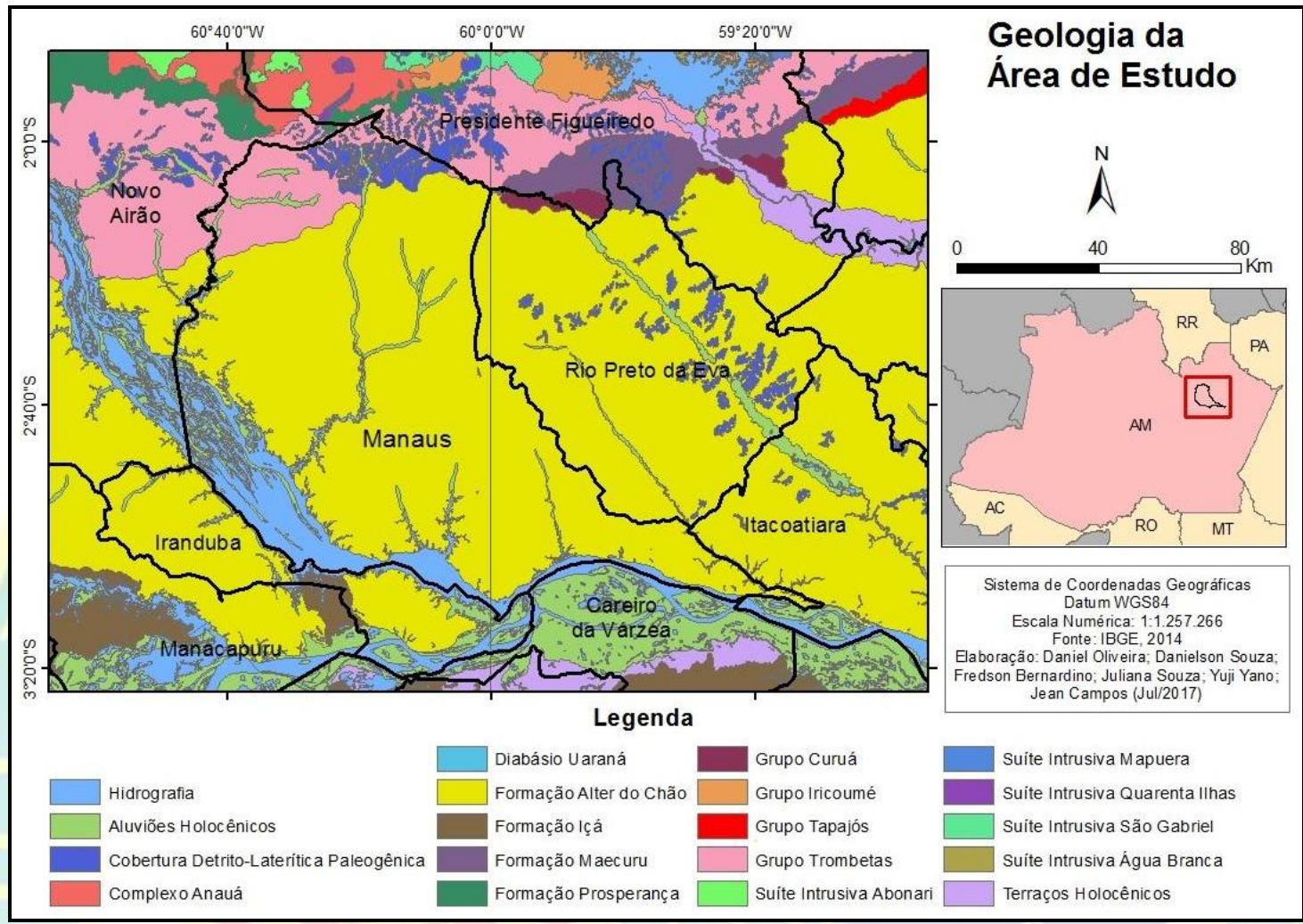

Fonte: Adaptado de OLIVEIRA NETO et al. (2017).

A questão do sítio e a ocupação na Amazônia, em especial o meio fluvial, fica clara nas análises do geógrafo Sternberg (1998) que destaca o contraste entre as "várzeas" e as "terras firmes". Sendo as várzeas planícies fluviais com inundação sazonal, por cerca de seis meses ao ano, formação predominante em Careiro da Várzea. Já as "terras firmes", são uma terminologia regional amazônica que, geomorfologicamente, é denominada como baixos platôs [amazônicos], caracterizam-se por superarem as maiores cheias da região, dificilmente são inundados, salvo eventos extremos, esse tipo de formação é predominante em Iranduba.

As várzeas amazônicas têm formações de origem sedimentar, geradas pelos depósitos dos rios que as cortam, no caso do município de Careiro da Várzea, o rio Amazonas. A cidade está localizada, conforme típico desse rio, em uma várzea e uma ilha, denominada Ilha do Careiro. O interior desta ilha é descrito com um alteamento das bordas formando um perfil característico de prato, e no centro é possível a acomodação de lagos mais ou menos rasos, de perímetro rendilhado, que se retraem no período de vazante e se dilatam no período de enchente (STERNBERG, 1998).

Dessa forma, Careiro da Várzea possui este topônimo não por outro motivo senão o de estar situado predominantemente numa área de várzea, dispondo de planície inundável por cerca de metade do ano, sendo limitado pelo rio Amazonas, de águas turvas, tendo como um de seus atributos o de transportar grande carga de sedimentos, fazendo a área sazonalmente inundável um depósito de sedimentos. Essa dinâmica permite a existência de solos férteis à prática da agricultura de várzea, por conta do depósito de materiais finos como 
silte e argila, sobre as quais é comum verificar culturas de ciclo curto. Ressaltando que tal ciclo de cultura é limitado pelo regime do rio (Mapa 03).

Mapa 03: Mapa hipsométrico da área de estudo.

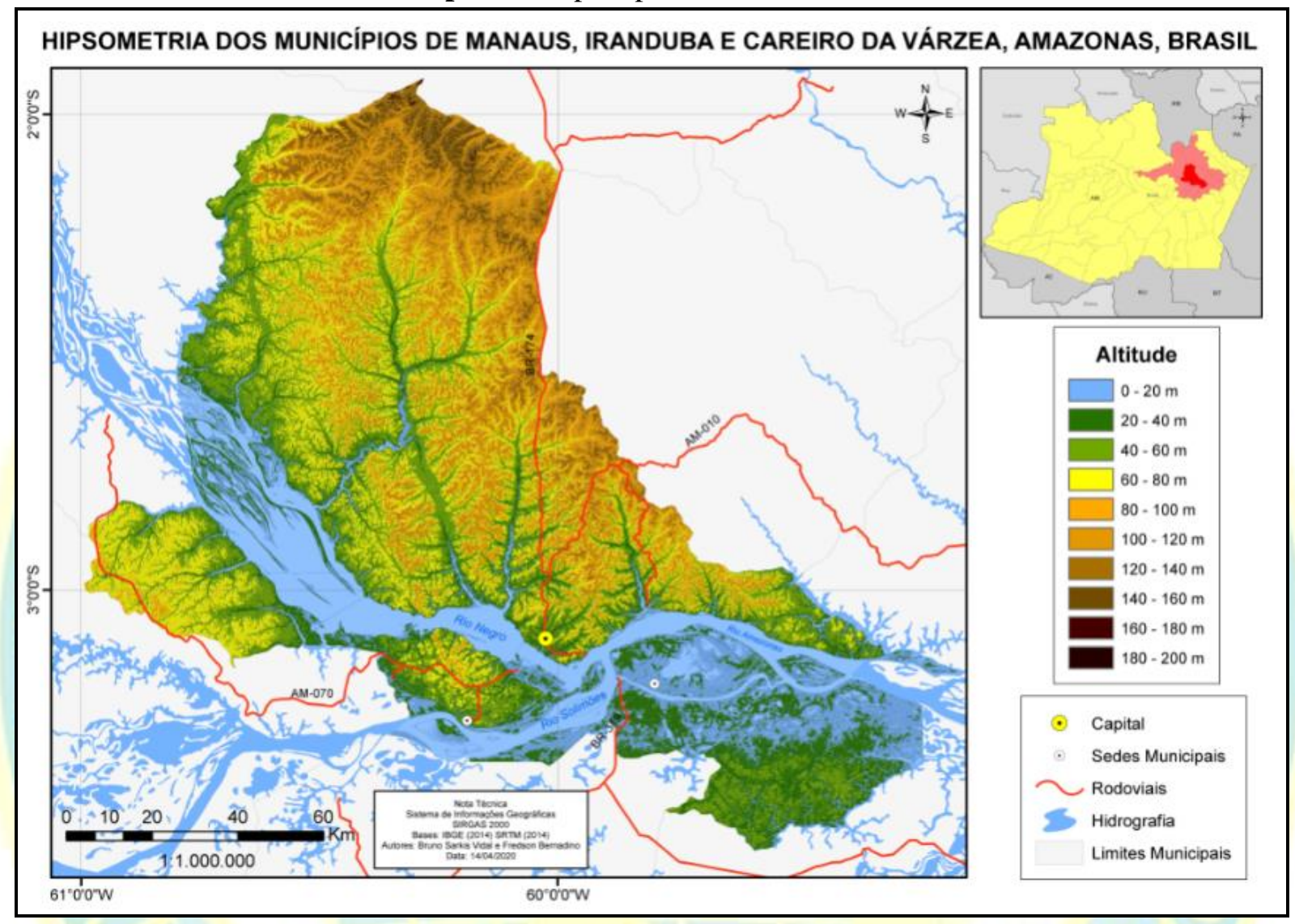

Fonte: SRTM (2010), IBGE (2010). Elaboração.: Vidal e Bernardino (abr/2020).

Essas várzeas compõem uma unidade geomorfológica alóctone, portanto seu material (pouco consolidado) não provém da degradação da rocha-matriz da própria localidade e sim da desagregação do material das vertentes andinas e transportado pelo rio Amazonas. Esse material é depositado nas margens do rio, constituindo uma acreção lateral. É nas margens dos rios onde também prevalece a ocupação ribeirinha por conta da fertilidade do solo e do acesso às grandes vias fluviais.

No que concerne especificamente ao Careiro da Várzea, é pertinente a análise do que se denominou de "cidade anfíbia" (LIMA, 2014, p. 288), ou seja, uma cidade que passa uma parte do ano inundada por conta da dinâmica fluvial traduzida nos regimes de enchente e vazante e que não atrai as forças que compõem o processo de metropolização do espaço em sua face mais visível. Dessa forma, a cidade do Careiro da Várzea é marcada pela dinâmica fluvial onde, no período de cheias excepcionais, fica completamente inundada, inclusive sua praça principal e a igreja matriz (FIGURA 02 e 03). 
Figura 02: Cidade do Careiro da Várzea alagada no ano de 2014. A) Praça e entrada principal da cidade; B) Igreja Matriz da cidade.

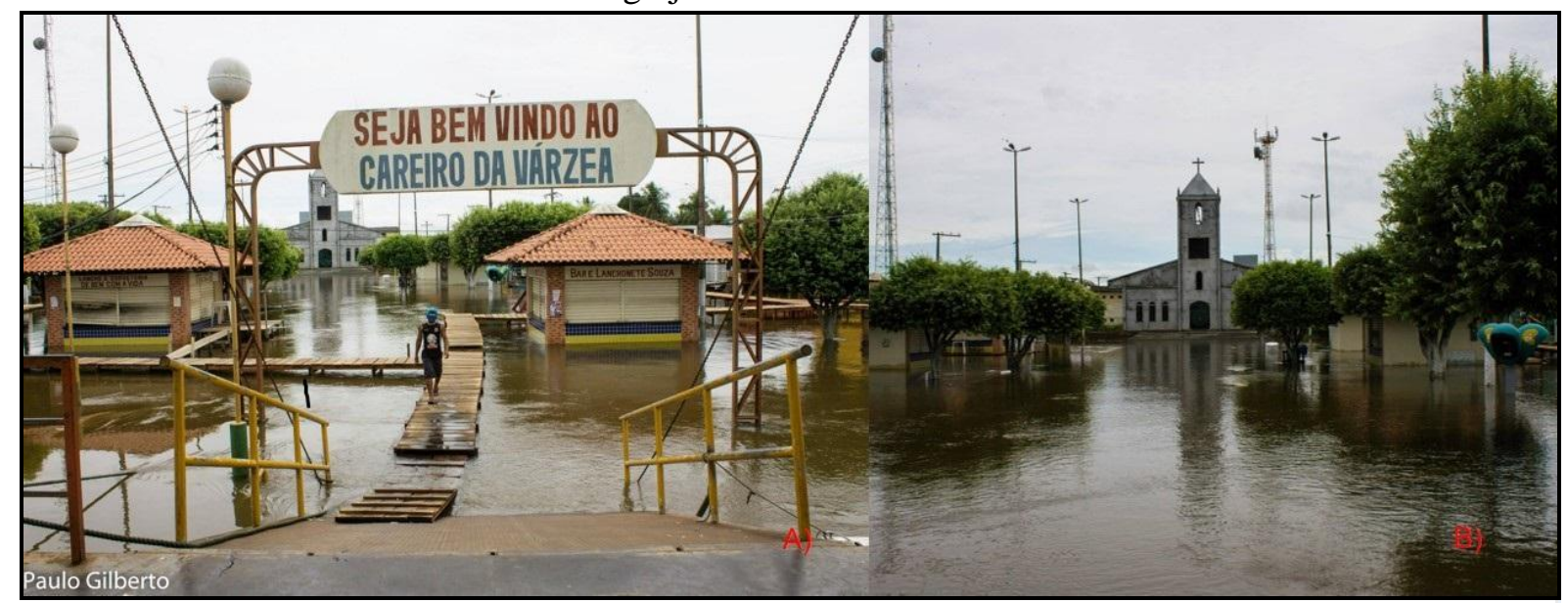

Fonte: Gilberto (2014). Org.: Bernardino (mai/2017).

Figura 03: Cidade do Careiro da Várzea alagado no ano de 2017. A) Praça e entrada principal da cidade; B) Igreja Matriz da cidade.

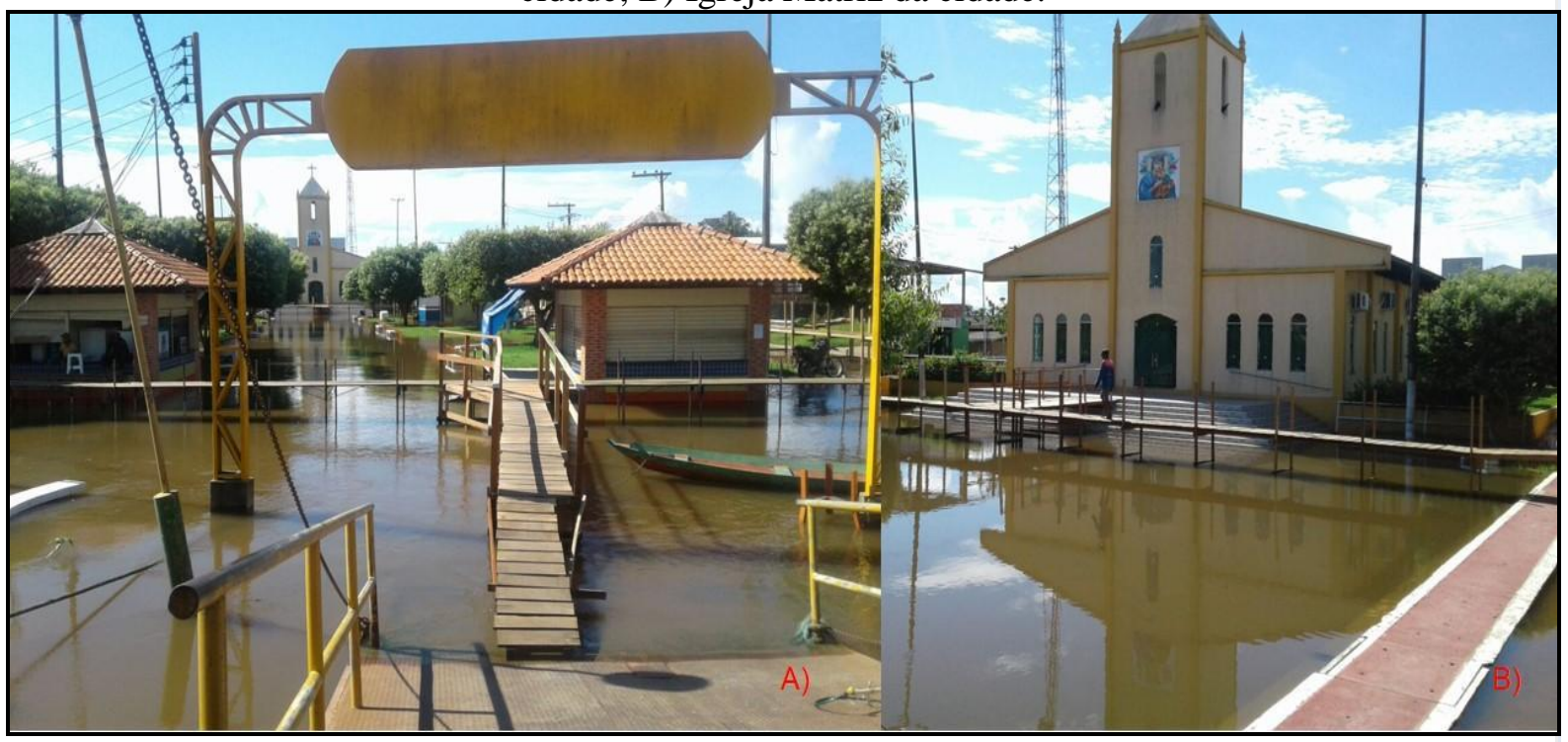

Fonte: Cardoso (2017). Org.: Bernardino (mai/2017).

Assim, a sazonalidade, se por um lado auxilia na produção agrícola, por outro, quando inundada, dificulta a vida cotidiana, a habitação, dentre outros aspectos, inviabilizando a expansão da área urbana, bem como algum planejamento que vise o avanço de expressões espaciais metropolitanas que integrem espacialmente Careiro da Várzea à Manaus, tendo em vista que há outras opções de seletividade, como Iranduba, à expansão da metrópole. Ressalte-se que esse tipo de estrutura inundável não inviabiliza o uso da terra, mas demanda maior apreensão técnica e muitos investimentos para a adequação do território ao capital, mesmo com a proximidade topográfica com a metrópole.

Trata-se, portanto, de um contexto diferente de Iranduba que tem em seu território uma predominância de terra firme, influenciado de forma tão expressiva pela dinâmica dos rios (MAGALHÃES, 
2011). Entretanto, oferece viabilidade de ocupação, inclusive permitindo o processo de expansão da metrópole, conforme está sendo observado. Nesse sentido, o município de Iranduba faz parte do interesse para usufruto desta capacidade de abrigar os processos urbanos/metropolitanos e de maior articulação com Manaus, sendo marco desse interesse a Ponte Jornalista Phelippe Daou.

Portanto, como já sugerido, a discussão perpassa a dimensão da tecnosfera, pois reflete sobre as interações realizadas pela sociedade a nível de segunda natureza, trata-se de possibilidades de se lançar mão de saber-fazeres para promoção de uma porção do meio à uma reestruturação das condições de produção principalmente promotores imobiliários - , está ocorrendo em maior grau em Iranduba. Porém, também se deve questionar sob o caráter da psicosfera (SANTOS, 2006). Esta compreende o mundo dos homens em termos de "interesses" - neste caso, pela ideologia - e constrói as condições de legitimação das ações da sociedade. Isto é, a promoção realizada pelo Estado em Iranduba em detrimento de Careiro da Várzea tem caráter político e econômico e a questão do sítio é secundária numa perspectiva de instância social.

Não obstante, a geomorfologia da área de estudo também pode ser fator a se relacionar à apreensão de sítio. Dessa forma, Manaus e Iranduba estão predominantemente na unidade geomorfológica do Planalto Rebaixado do Rio Negro/Uatumã o que significa que os municípios estão eximidos de grandes impactos em relação à dinâmica fluvial (Mapa 04).

Mapa 04: Mapa das unidades geomorfológicas da área de estudo.

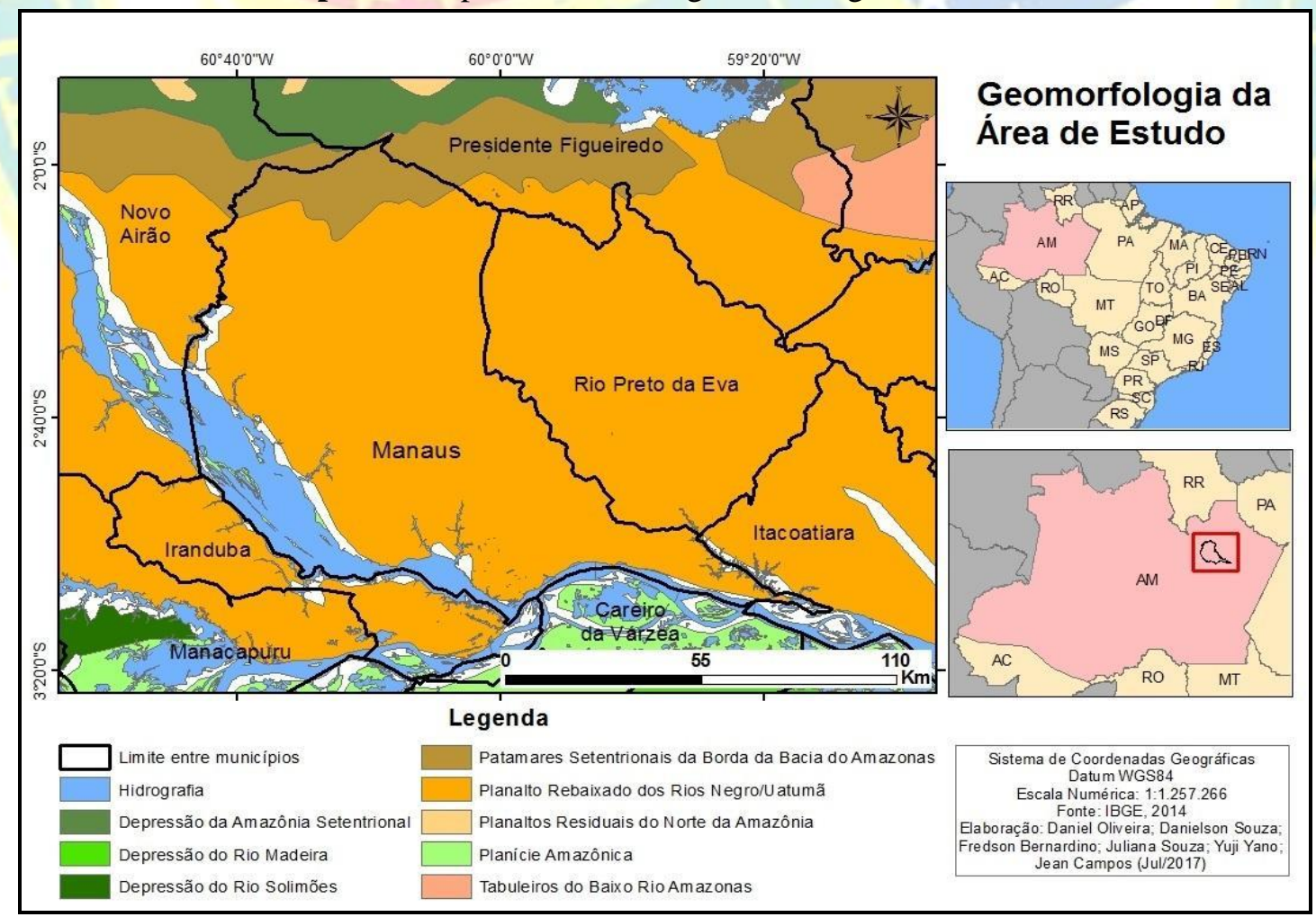

Fonte: Adaptado de OLIVEIRA NETO et al. (jul/2017). Org.: Bernardino (jul/2017). 
Careiro da Várzea, diferentemente da metrópole e de Iranduba, encontra-se na Planície Amazônica da qual possibilita o alagamento no período de cheia, dificultado o modelo de operação do circuito superior da economia urbana nas margens dos rios nesse período. Esse circuito diz respeito às grandes firmas, inserção financeira e demais atividades com alto teor de burocracia e modernização (SANTOS 2008).

Por fim, o que se confirma é um processo de intensificação da continuidade Manaus-Iranduba mesmo com a descontinuidade espacial do rio Negro, a qual foi rompida via Ponte Jornalista Phelippe Daou. A distinção é alta com relação ao Careiro da Várzea, apresentando sítio passível de inundação, o que sob a ótica dos agentes modeladores do espaço urbano, especialmente os proprietários fundiários, promotores imobiliários e Estado, é pouco valorizada quando em comparação com Iranduba (LIMA, 2014).

Demonstra-se, portanto, a importância da seletividade espacial como a prática que compreende a organização e atuação, tendo em vista as várias localizações e nexos que o meio técnico apresenta (CORRÊA, 1992). Essa prática se relaciona ao poder da decisão que não pode ser entendida como desconexa do "lugar", ou seja, além da perspectiva do espaço concreto, há de se associar com a dinâmica da sociedade e como as ideias se articulam, não se podendo prescindir dos contextos que envolvem os processos como por exemplo, no caso da Amazônia Ocidental e da RMM, o meio natural, mais especificamente, relacionado à dinâmica fluvial. Dessa forma, mesmo não se tratando de uma "determinação geográfica" ou de uma simples "naturalização do meio técnico", não se pode negar sua influência nas estruturas e nos processos da formação do espaço urbano/metropolitano na Amazônia Ocidental, inclusive, sendo considerado no PDIRMM (2010). De todo modo, ressalta-se que a dinâmica do meio técnico tem prevalência na relação sociedade/espaço, pois é justamente este que permite a seletividade espacial.

\section{CONSIDERAÇÕES FINAIS}

Ressaltou-se o entendimento sobre as tendências do processo de metropolização do espaço de dois municípios amazônicos no contexto da RMM, perfazendo uma relação com suas singularidades tendo como atributo principal a análise da seletividade espacial e como esta influencia na dinâmica desse lugar no que concerne aos processos de metropolização do espaço.

Invariavelmente a metrópole exerce por meio de fatores políticos, econômicos, culturais, dentre outros, a função de interlocutora com o território e o restante do mundo. A metrópole Manaus também exerce essa função na Amazônia Ocidental, sediando as inserções e dinâmicas advindas de um processo maior, a globalização. Apesar da capital do estado do Amazonas ainda não vivenciar plenamente a conurbação com a cidade de Iranduba, é possível afirmar que esse processo já está sendo encaminhado, quando se consideram os adensamentos, a ampliação do comércio e serviços e o avanço do setor imobiliário, com indução promovida pelo Estado, por meio do estabelecimento de obras de infraestrutura e equipamentos coletivos. 
Não obstante, as características desta globalização são gradualmente pulverizadas, ainda que não totalmente em sua dimensão material, para o restante da RMM mesmo sem a continuidade material com a metrópole, pois há disseminação de elementos e valores, principalmente imateriais, mas, ainda assim, metropolitanos.

Tanto Iranduba como Careiro da Várzea são municípios limítrofes à metrópole Manaus e além de constituírem as cidades mais próximas a ela, também compreendem características diferentes no que se refere à difusão do meio técnico em suas expressões espaciais. Como já explicitado, a dinâmica fluvial constitui um dos fatores que influenciam na seletividade espacial tendo como escopo o processo de metropolização do espaço na Amazônia Ocidental.

A RMM, em sua dimensão jurídica e territorial superlativa, dispõe de extensas áreas não urbanizadas e muito mais ainda não metropolizadas. A seletividade espacial, portanto, aparece como fator relevante na metropolização do espaço. Por isso, a valorização do espaço ganha relevância onde os agentes modeladores e consumidores que dinamizam o espaço urbano, como os promotores imobiliários, proprietários fundiários e o Estado, voltam-se para áreas não ocupadas e mais propícias aos interesses vinculados à produção e reprodução de capital, direcionando-se, neste caso, a Iranduba.

\section{REFERÊNCIAS}

BRAGA, Eduardo Henrique F. A (re)produção da metrópole na Amazônia. Manaus, a cidade que atravessa o rio. Dissertação (Mestrado em Geografia) defendido junto ao Instituto de Filosofia, Ciência Humanas e Sociais pelo Programa de Pós-graduação em Geografia da Universidade Federal do Amazonas. Manaus: 2019.

CATAIA, Márcio A. As Desigualdades e a Tecnificação do Território Brasileiro. In: Ana Fani Alessandri

Carlos (Org.). Ensaios de Geografia Contemporânea. Milton Santos, Obra Revisitada. 1ed. São Paulo: Hucitec/Imprensa Oficial/Edusp, 2001, v. 1, p. 170-177.

CORRÊA, Roberto L. O Espaço Urbano. São Paulo: Ática, 2003.

CORRÊA, Roberto L. Corporação, práticas espaciais e gestão do território. AIGeo, v.15, 1992. Disponível: <https://revistas.ufrj.br/index.php/aigeo/article/view/5934>. Acesso em: 13 de abr. de 2020.

DI MÉO, Guy. Introdução ao debate sobre a metropolização. Confins [Online], 4 | 2008 - DOI: 10.4000/confins.5433. Posto online no dia 13 Novembro 2008. Disponível: 〈http://confins.revues.org/5433〉.

EHNERT, Alexandre R. von. A Região Metropolitana de Manaus e as migrações pendulares. Dissertação (Mestrado em Geografia Humana) defendida junto à Faculdade de Filosofia, Letras e Ciências Humanas da Universidade de São Paulo. São Paulo: 2011.

GOVERNO DO ESTADO DO AMAZONAS. Plano Diretor Integrado da Região Metropolitana de Manaus - PDIRMM. Manaus, 2010.

LENCIONI, Sandra. Metrópole, metropolização e regionalização. Rio de Janeiro: Consequência, 2017. 
LENCIONI, Sandra. Metropolização do Espaço: processos e dinâmicas. São Paulo, 2012, (mimeo).

LIMA, Marcos Castro de. A cidade, o urbano e o rio na Amazônia. Revista ACTA Geográfica, ANO II, $\mathrm{n}^{\circ} 3$, jan./jun. de 2008. p.107-117.

LIMA, Marcos Castro de. Quando o amanhã vem ontem: a institucionalização da região metropolitana de Manaus e a indução ao processo de metropolização do espaço na Amazônia ocidental. Tese (Doutorado em Geografia Humana) defendida junto à Faculdade de Filosofia, Letras e Ciências Humanas da Universidade de São Paulo. São Paulo: setembro, 2014.

MAGALHÃES, Regiane C. As características físicas, químicas, mineralógicas e hidráulicas do solo e sua susceptibilidade ao processo de terras caídas: comunidade Divino Espírito Santo - Iranduba/AM. Dissertação (Mestrado em Geografia) defendida junto ao Instituto de Ciências Humanas e Letras da Universidade Federal do Amazonas. Manaus: 2011.

MOREIRA, Ruy. Uma ciência das práticas e saberes espaciais. Rev. Tamoios, São Gonçalo (RJ), ano 13, n. 2, págs. 26-43, jul-dez 2017.

OLIVEIRA NETO, Daniel; SOUZA, Danielson; BERNARDINO, Fredson A. S.; SOUZA, Juliana; YANO, Yuji. Estudo de Impacto de Vizinhança - EIV de RUBI da Amazônia Industrias Quimicas Ltda. Manaus, 2017 (mimeo).

PNUD - Programa das Nações Unidas para o Desenvolvimento. Relatório do Desenvolvimento Humano 2019. Além do rendimento, além das médias, além do presente: As desigualdades no desenvolvimento humano no século XXI. Nova Iorque: PNUD, 2019. Disponível: <http://hdr.undp.org/sites/default/files/hdr 2019 pt.pdf $>$. Acesso em: 20 de out. de 2020.

ROCHA, André. Seletividade espacial das políticas públicas e o território urbano - algumas reflexões. Geo UERJ - Ano 14, nº. 23, v. 1, $1^{\circ}$ semestre de 2012 p. 99-113.

ROMAnelli, C.; ABIKO, A. K. Processo de Metropolização no Brasil. São Paulo: EPUSP, 2011. Disponível: 〈http://publicacoes.pcc.usp.br/Textos.Tecnicos〉. Acesso em 27 de junho de 2017

SANTOS, Milton. A natureza do espaço. Técnica e tempo. Razão e emoção. São Paulo: Edusp, 2006.

SANTOS, Milton. O espaço dividido. Os dois circuitos da economia urbana dos países subdesenvolvidos. $4^{\mathrm{a}}$ ed. São Paulo: Edusp, 2008.

SOUSA, Isaac. A ponte Rio Negro e a Região Metropolitana de Manaus: adequações no espaço urbano-regional à reprodução do capital. Tese (Doutorado em Geografia Humana) defendida junto à Faculdade de Filosofia, Letras e Ciências Humanas da Universidade de São Paulo. São Paulo, 2013.

STERNBERG, Hilgard O'Rellly. A água e o homem na várzea do careiro. $2^{\text {a }}$ ed. Belém-PA: PRN/MCT/CNPq, Museu Paraense Emílio Goeldi, Coleção Friedrich Katzer, 1998.

THÉRY, Hervé; MELLO-THÉRY, Neli A. de. Atlas do Brasil. Disparidades e Dinâmicas do Território. $2^{\mathrm{a}}$ ed. $2^{\mathrm{a}}$ imp. São Paulo: Edusp, 2014. 